\title{
NOTA
}

\section{EROSIVIDADE, COEFICIENTE DE CHUVA, PADRÕES E PERÍODO DE RETORNO DAS CHUVAS DE QUARAÍ, RS ${ }^{(1)}$}

\author{
Marcos Gabriel Peñalva Bazzano ${ }^{(2)}$, Flávio Luiz Foletto Eltz ${ }^{(3)} \&$ \\ Elemar Antonino Cassol ${ }^{(4)}$
}

\begin{abstract}
RESUMO
O conhecimento da potencialidade das chuvas em causar erosão é necessário para planejamento de atividades agrícolas e de engenharia civil. Para a localidade de Quaraí (RS), foram determinados a erosividade da chuva e a relação com a precipitação e o coeficiente de chuva, os padrões hidrológicos e o período de retorno das chuvas. Utilizaram-se dados pluviográficos diários do período 1966-2003. Para cada chuva erosiva, foram separados os segmentos do pluviograma com a mesma intensidade e registrados os dados em planilha. Com o programa Chuveros, foram calculadas as erosividades mensal, anual e média das chuvas pelo índice $\mathbf{E I}_{30}$, no Sistema Internacional de Unidades, e os padrões hidrológicos de chuva, bem como o coeficiente de chuva. Foram realizadas correlações de Pearson e regressões lineares simples entre o índice de erosividade $\mathrm{EI}_{30}$ e os valores médios mensais (p) e anuais (P) de precipitação e do coeficiente de chuva ( $R c)$. Foi calculada a intensidade máxima da chuva pelo método da distribuição extrema tipo 1 para durações de chuva de 1/6, 1/3, 1/2, 1, 2, 4, 8, 12, 24 e $48 \mathrm{~h}$ e períodos de retorno da chuva de 2, 5, 10, 20, 50 e 100 anos. Foram ajustadas equações que relacionam a intensidade máxima e a duração da chuva para os períodos de retorno da chuva de $2,5,10,20,50$ e 100 anos, pelo método de regressão linear simples, e construído o gráfico que relaciona essas características da chuva. $\mathrm{O}$ valor médio anual de $\mathbf{E I}_{30}$ (fator R da USLE) calculado para Quaraí foi de $9.292 \mathrm{MJ} \mathrm{mm} \mathrm{ha}^{-1} \mathrm{~h}^{-1}$ ano-1. $^{-1}$. Obtiveram-se as equações $\mathrm{EI}_{30}=-754,37+13,50$ p $\left(\mathrm{r}^{2}=0,85\right)$ e $\mathrm{EI}_{30}=-47,35+82,72 \mathrm{Rc}$ $\left(R^{2}=0,84\right)$. Em relação ao total das chuvas estudadas, $44 \%$ do número e $90 \%$ do volume foram erosivas. Do número total das chuvas erosivas, $51 \%$ foram do padrão hidrológico avançado, $25 \%$ do intermediário e $24 \%$ do atrasado, ao passo que, do
\end{abstract}

\footnotetext{
(1) Parte da Tese de Mestrado em Ciência do Solo apresentada pelo primeiro autor à Universidade Federal de Santa Maria UFSM. Recebido para publicação em janeiro de 2006 e aprovado em maio de 2007.

${ }^{(2)}$ Engenheiro-Agrônomo, MSc. Asociación para la Agricultura Sostenible en base a Siembra Directa. La Paz 302, Col. Alameda, C.P. 38050, Celaya, Guanajuato, México. E-mail: marcos.penalva@gmail.com

(3) Professor Titular do Departamento de Solos, Universidade Federal de Santa Maria - UFSM. CEP 97105-900 Santa Maria - RS. Bolsista do CNPq. feltz@ccr.ufsm.br

(4) Professor Adjunto do Departamento de Solos, Faculdade de Agronomia, Universidade Federal de Rio Grande do Sul - UFRGS. CEP 90001-970 Porto Alegre (RS). Bolsista do CNPq. E-mail: cassolea@orion.ufrgs.br
} 
volume total das chuvas erosivas, 57 \% foram do padrão avançado, $25 \%$ do intermediário e $18 \%$ do atrasado. Das chuvas erosivas, $57 \%$ da erosividade correspondeu a chuvas do padrão avançado, $25 \%$ a chuvas do padrão intermediário e $18 \%$ a chuvas do padrão atrasado.

Termos de indexação: energia cinética, intensidade da chuva, duração da chuva, freqüência da chuva, índice $\mathrm{EI}_{30}$.

\title{
SUMMARY: EROSIVITY, RAINFALL COEFFICIENT AND PATTERNS AND RETURN PERIOD IN QUARAI, RS, BRAZIL
}

\begin{abstract}
The planning of agricultural and civil engineering activities must be based on knowledge of rainfall erosion potential. For Quarai, $R S$, Brazil, the rainfall erosivity and its relationship with precipitation and rainfall coefficient, rainfall patterns and rainfall return period were determined. Daily rainfall data from the 1966-2003 period were used. For each erosive rainfall the segments of the rainfall chart with the same intensity were separated and the data recorded in a worksheet. The mean precipitation and rainfall patterns were estimated, as well as the monthly and annual erosivity by the $\mathrm{EI}_{30}$ index (International System of Units), using the software Chuveros. The rainfall coefficient was calculated. Pearson correlations and linear regressions between the erosivity index $\mathrm{EI}_{30}$ and the mean annual precipitation and rainfall coefficient $(R c)$ were performed. The rainfall maximum intensity was calculated by the method of extreme distribution type I for different rainfall durations $(1 / 6,1 / 3,1 / 2,1,2,4,8,12,24$ and $48 \mathrm{~h})$ and rainfall return periods $(2,5,10,20,50$ and 100 years). Equations were adjusted that relate the maximum intensity and rainfall duration to all return periods, by the method of simple linear regression, and the rainfall characteristics related in a graph. The mean annual values of $E I_{30}$ ( $R$ factor of USLE) determined for Quarai, $R S$, Brazil, was 9,292 $\mathrm{MJ} \mathrm{mm} \mathrm{ha}^{-1} \mathrm{~h}^{-1}$ year ${ }^{-1}$. The following equations were obtained: $E I_{30}=-754.37+13.50 p\left(r^{2}=0.85\right)$ and $E I_{30}=-47.35+82.72 R c\left(r^{2}=0.84\right)$. In relation to the total precipitation studied, $44 \%$ of the number of rainfalls and $90 \%$ of the volume were erosive. Of the total rainfalls evaluated, $44 \%$ of the number and $90 \%$ of the volume were erosive. Of the total erosive rainfall events, $51 \%$ had an advanced, $25 \%$ had an intermediate, and $24 \%$ had a delayed hydrological pattern. Of the total volume of erosive rainfalls, $57 \%$ showed and advanced pattern, $25 \%$ intermediate, and $18 \%$ a delayed pattern.
\end{abstract}

Index terms: kinetic energy, rainfall, rainfall intensity, rainfall duration, rainfall frequency, $\mathrm{EI}_{30}$ index, rainfall coefficient.

\section{INTRODUÇÃO}

A erosão hídrica é a conseqüência da interação da chuva com o solo, ou seja, é a resultante do poder da chuva em causar erosão e da capacidade do solo em resistir a esta. Ao potencial da chuva em causar erosão chama-se erosividade.

$\mathrm{Na}$ primeira metade do século passado foram iniciados esforços para estimar as perdas de solo sob diferentes condições de clima, solo e manejos, visando a um planejamento conservacionista. Em 1954, surgiu nos Estados Unidos, a partir do aperfeiçoamento de diferentes modelos, a Equação Universal de Perdas de Solo (USLE), também conhecida como equação de Wischmeier \& Smith (1978), na qual o fator R, índice de erosividade, expressa o potencial da chuva de provocar a erosão do solo, sendo variável de região para região.
Segundo Wischmeier (1959), o índice de erosividade $\mathrm{EI}_{30}$ expressa a relação entre a intensidade e a energia cinética da chuva e se correlaciona bem com as perdas de solo por erosão. Morais et al. (1988a), estudando três localidades do Rio Grande do Sul, concluíram que o índice de erosividade $\mathrm{EI}_{30}$ (Wischmeier \& Smith, 1978) foi adequado para estimar o potencial erosivo da chuva.

Morais et al. (1988a), Lago (2000), Cassol et al. (2004a,b) e Roncato et al. (2004) determinaram o índice $\mathrm{EI}_{30}$ de várias localidades do Rio Grande do Sul a partir de dados pluviográficos. A determinação desse índice é um processo trabalhoso, que implica ter pluviogramas de vários anos para determinar a energia cinética e intensidade máxima das chuvas. Em muitas ocasiões não se contam com registros de pluviógrafo e sim com dados de pluviômetro. A fim de facilitar a determinação do índice de erosividade, Oliveira Júnior \& Medina (1990), Morais et al. (1988b, 
1991), Silva \& Dias (2003), entre outros, relacionaram o índice $\mathrm{EI}_{30}$ com a precipitação média anual $(\mathrm{P})$ e o coeficiente da chuva expresso como Rc (igual ao quadrado da precipitação média mensal, $\mathrm{p}^{2}$, dividido pela precipitação média anual, $\mathrm{P}$ ), proposto por Fournier (1956) e modificado por Lombardi Neto (1977). Em várias localidades, as correlações entre esses parâmetros não foram significativas (Albuquerque, 1992; Bertol, 1993, 1994).

Perdas de solo e danos em infra-estrutura e obras de engenharia hidráulica ocorrem freqüentemente por causa da chuva. Eficientes dimensionamentos de obras hidráulicas e conservacionistas podem ser realizados quando são considerados aspectos de risco e freqüência da chuva. A análise de distribuição de freqüência permite estimar o período de retorno de um evento máximo anual de chuva, que pode ser definido como o período, em anos, em que o referido evento pode ser igualado ou excedido, pelo menos uma vez, em média (Eltz et al., 1992). Além disso, os padrões hidrológicos de chuva, classificados em padrão avançado, intermediário e atrasado, quando a localização dos picos de maior intensidade está no início, meio ou fim do período de duração das chuvas, respectivamente (Horner \& Jens, 1941), podem mudar de uma região para outra, causando diferentes perdas de solo (Mehl et al., 2001), e ter diferentes períodos de retorno (Mehl et al., 2001; Moreti et al., 2003).

O conhecimento das características da chuva permite a planificação mais segura de estruturas de conservação de solo (terraços, curvas de nível) e de práticas agrícolas que visem à conservação do solo por meio de manutenção de sua cobertura, assim como outras obras (barragens, canais escoadouros), e de estruturas hidráulicas de fluxo para águas pluviais, o que justifica sua determinação.

Assim, os objetivos deste trabalho foram determinar: erosividade da chuva e relação com a precipitação e o coeficiente de chuva; padrões hidrológicos da chuva; e período de retorno da chuva para a localidade de Quaraí, no Estado do Rio Grande do Sul.

\section{MATERIAL E MÉTODOS}

Foram calculados a erosividade da chuva, o coeficiente de chuva e sua relação com a erosividade, a relação da erosividade com a precipitação, determinados os padrões e os períodos de retorno das chuvas da localidade de Quaraí, no Estado de Rio Grande do Sul, a partir de dados pluviográficos da estação meteorológica de Quaraí, os quais foram cedidos pela Fepagro (Fundação Estadual de Pesquisa Agropecuária), de uma série de 38 anos, correspondente ao período 1966-2003.

Quaraí localiza-se na região fisiográfica denominada Campanha. A estação meteorológica do local está situada a uma altitude de 100 m, latitude sul de $30^{\circ} 23^{\prime}$ ' e longitude oeste de $56^{\circ} 26$ '. Segundo a classificação de Köppen, o clima é Cfa, ou seja, temperado úmido sem estiagem, com temperaturas média, máxima e mínima anual de 19,6, 24,5 e $13,7^{\circ} \mathrm{C}$, respectivamente, e precipitação média anual de $1.513 \mathrm{~mm}$, no período 1971-2000 (Ipagro, 1989).

Conforme sugerido por Cabeda (1976), foram selecionadas as chuvas individuais erosivas, considerando-se chuvas individuais aquelas separadas de outras por intervalo de no mínimo seis horas com precipitação inferior a $1 \mathrm{~mm}$ e erosivas quando a precipitação total for igual ou superior a $10 \mathrm{~mm}$ ou quando a precipitação for igual ou superior a $6 \mathrm{~mm}$ em 15 min ou menos de chuva.

A partir dos pluviogramas diários, cada chuva erosiva individual foi separada em segmentos uniformes, ou seja, segmentos de mesma inclinação (intensidade constante). Os dados das chuvas foram registrados manualmente em planilha, segundo Freitas \& Madeira Neto (1980), onde foram anotadas as horas em que houve variação de intensidade e a chuva acumulada até aquele momento. A amplitude de registro dos pluviogramas foi de $10 \mathrm{~mm}$ de precipitação, com unidade de $0,1 \mathrm{~mm}$. O tempo de registro foi de $24 \mathrm{~h}$, com unidades de $10 \mathrm{~min}$, realizando-se a leitura da precipitação com unidades de 5 min.

Por meio do programa Chuveros, elaborado por Elemar Antonino Cassol da UFRGS (Universidade Federal do Rio Grande do Sul), e planilhas de cálculo, foram estimadas as erosividades mensal, anual e média das chuvas pelo índice $\mathrm{EI}_{30}$ (Wischmeier \& Smith, 1958), no Sistema Internacional de Unidades (Foster et al., 1981). Os cálculos do programa foram realizados da forma explicitada a seguir.

A energia cinética de cada segmento uniforme de uma chuva erosiva individual é determinada por:

$$
\mathrm{EC}_{\mathrm{s}}=\mathrm{EC} \mathrm{h}
$$

em que $\mathrm{EC}_{\mathrm{s}}$ é a energia cinética no segmento de chuva, em MJ ha- ${ }^{-1}$ EC é a unidade de energia cinética e h é a quantidade de chuva no segmento uniforme, $\mathrm{em} \mathrm{mm}$.

A equação para cálculo da energia cinética é a seguinte:

$$
\mathrm{EC}=0,119+0,0873 \log \mathrm{I}
$$

em que EC é a energia cinética por $\mathrm{mm}$ de chuva, em MJ ha ${ }^{-1} \mathrm{~mm}^{-1}$, e Ié a intensidade da chuva no segmento uniforme (intensidade constante), em $\mathrm{mm} \mathrm{h}^{-1}$.

A energia cinética total da chuva erosiva individual foi calculada pela expressão:

$$
\mathrm{EC}_{\mathrm{t}}=\Sigma \mathrm{EC}_{\mathrm{s}}
$$

em que $\mathrm{EC}_{\mathrm{t}}$ é a energia cinética total da chuva erosiva individual, em MJ ha' ${ }^{-1}$ e $\Sigma \mathrm{EC}_{\mathrm{s}}$ é o somatório da energia cinética de cada segmento da chuva, em $\mathrm{MJ} \mathrm{ha}^{-1}$. 

por:

O índice de erosividade de cada chuva foi calculado

$$
\mathrm{EI}_{30}=\mathrm{EC}_{\mathrm{t}} \mathrm{I}_{30}
$$

em que $\mathrm{EI}_{30}$ é o índice de erosividade da chuva erosiva individual, em $\mathrm{MJ} \mathrm{mm} \mathrm{ha}^{-1} \mathrm{~h}^{-1} ; \mathrm{EC}_{\mathrm{t}}$ é a energia cinética total da chuva, em $\mathrm{MJ} \mathrm{ha}^{-1}$; e $\mathrm{I}_{30}$ é a intensidade máxima da chuva em um período de $30 \mathrm{~min}$, em $\mathrm{mm} \mathrm{h}^{-1}$, ou seja, a quantidade máxima de chuva em um período de 30 min multiplicada por 2 , determinada a partir dos dados obtidos do pluviograma.

Os valores mensais dos índices de erosividade $\mathrm{EI}_{30}$ são a média dos meses para a localidade. O valor médio anual do índice de erosividade $\mathrm{EI}_{30}$ é a média dos anos do período estudado.

Os valores médios mensais da precipitação e do índice de erosividade foram expressos como percentagens do valor médio anual da precipitação e do índice de erosividade, respectivamente, para obter a curva de distribuição acumulada mensal da precipitação e do índice de erosividade, conforme Wischmeier \& Smith (1958).

O coeficiente de chuva (Rc) foi calculado por meio da equação proposta por Lombardi Neto (1977):

$$
\mathrm{Rc}=\mathrm{p}^{2} \mathrm{P}^{-1}
$$

em que p representa a precipitação média mensal $(\mathrm{mm})$ e P a precipitação média anual $(\mathrm{mm})$.

Foram realizadas análises de correlação de Pearson e de regressão linear simples entre o índice de erosividade $\mathrm{EI}_{30}$ e cada um dos valores médios anuais de precipitação e coeficiente de chuva, utilizando o programa estatístico SAS (Statistical Analysis System), versão 8.02 para Windows, com o apoio do manual para análises estatísticas de dados experimentais (Rebolledo, 2002).

O padrão da chuva foi determinado pelo programa Chuveros, separando-se as chuvas de acordo com os padrões de chuva avançado, intermediário e atrasado, da classificação proposta por Horner \& Jens (1941). Padrão avançado, intermediário e atrasado caracteriza-se quando a localização do pico de maior intensidade está no início (primeiro terço), meio (segundo terço) ou fim (terceiro terço) do período de duração da chuva, respectivamente. Também foi calculada a percentagem do total das chuvas que representa cada padrão.

O período de retorno ( $\mathrm{T})$, definido como o período em anos em que um evento máximo anual pode ser igualado ou excedido pelo menos uma vez, em média, a cada $\mathrm{T}$ anos, foi determinado segundo o método descrito em Eltz et al. (1992).

De acordo com Bedient \& Huber (1988), a função de densidade probabilística pode ser vista como:

$$
F(x)=\mathrm{e}^{-\mathrm{e}^{-\alpha(x-u)}},-\propto \leq \mathrm{x} \leq \propto
$$

em que $F$ é uma função de densidade probabilística; e, a base neperiana (2,712817); $\alpha$, um parâmetro de escala; e u (modal), um parâmetro de localização. Esses parâmetros se relacionam com a média $(\mu)$ e o desviopadrão $(\sigma)$ da intensidade máxima da chuva por:

$$
u=\mu-0,5772 \alpha^{-1}
$$

$\mathrm{e}$

$$
\alpha=\pi(\sigma \sqrt{ } 6)^{-1}
$$

O valor da intensidade máxima esperada para determinado período de retorno e duração da chuva é dado por:

$$
I=\mu+\mathrm{K} \sigma
$$

sendo $K$ o fator de freqüência, que se calcula por:

$$
\mathrm{K}=0,7797\left\{0,5772+\ln \left[\ln \left(T(T-1)^{-1}\right]\right\}\right.
$$

em que ln é o logaritmo neperiano e $T$ o período de retorno.

O período de retorno, $T$, desejado é calculado pela equação:

$$
T=1(1-F)^{-1}
$$

Assim, é possível calcular o período de retorno para uma determinada intensidade e duração da chuva.

Por meio do programa Chuveros, geraram-se os valores das quantidades máximas de chuva ocorridas durante $1 / 6,1 / 3,1 / 2,1,2$ e $4 \mathrm{~h}$, e a partir dos pluviogramas das chuvas de cada ano foram determinadas as quantidades máximas de chuva ocorridas durante 8, 12, 24 e 48 h em qualquer momento do período de tempo analisado. Nos intervalos menores (até $4 \mathrm{~h}$ ), as durações de chuva consideradas podem representar um período mais curto que a duração total de uma chuva individual, enquanto as durações maiores (oito ou mais horas) podem abranger mais de uma chuva individual. Os dados das intensidades máximas em cada duração de chuva foram testados pela distribuição extrema tipo I (Gumbel, 1958), com o programa Freqrisk, descrito em Kite (1988), que calculou a média $(\mu)$, o desviopadrão $(\sigma)$, o parâmetro a e o período de retorno para 2, 5, 10, 20, 50 e 100 anos. Para cada período de retorno, foram ajustadas equações polinomiais de segunda ordem com a forma:

$$
\log I=a+b(\log D)+c(\log D)^{2}
$$

em que log é o logaritmo base 10; I, a intensidade máxima da chuva, em $\mathrm{mm} \mathrm{h}{ }^{-1} ; D$, a duração da chuva, em horas; e $a, b$ e $c$, parâmetros de ajuste. Também foi ajustada a equação utilizada por Denardin et al. (1980), que relaciona as características intensidade da chuva, duração da chuva e período de retorno da chuva:

$$
I=\frac{a T^{b}}{(t+c)^{d}}
$$


em que Ié a intensidade máxima da chuva, em $\mathrm{mm} \mathrm{h}^{-1}$; $T$, o período de retorno, em anos; $t$, a duração da chuva, em horas; e $a, b, c$ e $d$, parâmetros de ajuste. O ajuste da equação (13) foi realizado por regressão múltipla linear após linearização com a forma:

$$
\log 1=\log a+b \log T-d \log (t+c)
$$

em que log é o logaritmo-base 10. Em virtude da associação com a variável independente $t$ na equação (14), o parâmetro $c$ não pôde ser estimado. Assim, atribuíram-se valores arbitrários ao coeficiente $c$, estimando-se os coeficientes $a, b$ e $d$ para cada caso, até se encontrar a equação com maior coeficiente de determinação múltipla $\left(\mathrm{R}^{2}\right)$, considerada a de melhor ajuste.

\section{RESULTADOS E DISCUSSÃO}

\section{Erosividade da chuva (índice $\mathrm{EI}_{30}$ ) e coeficiente de chuva (Rc)}

No quadro 1 são apresentados os valores mensais, anuais e médios do índice de erosividade $\mathrm{EI}_{30}$ da chuva, com os respectivos desvios-padrão e coeficientes de variação, bem como a amplitude de variação. $\mathrm{O}$ valor do fator R da USLE para Quaraí - valor médio anual da erosividade da chuva -é de $9.292 \mathrm{MJ} \mathrm{mm} \mathrm{ha}^{-1} \mathrm{~h}^{-1}$ $\mathrm{ano}^{-1}$. No período dezembro-março observou-se a maior erosividade média mensal, com valores do índice $\mathrm{EI}_{30}$ que variaram entre $1.072 \mathrm{e} 1.304 \mathrm{MJ} \mathrm{mm} \mathrm{ha}^{-1} \mathrm{~h}^{-1} \mathrm{mês}^{-1}$. Nos meses de julho e agosto ocorreu, em média, a menor erosividade (286 e $211 \mathrm{MJ} \mathrm{mm} \mathrm{ha}^{-1} \mathrm{~h}^{-1} \mathrm{mês}^{-1}$, respectivamente). O coeficiente de variação dos valores mensais foi muito alto, variando entre 91 e $169 \%$, enquanto o coeficiente de variação anual, embora menor, foi também muito alto, alcançando $48 \%$, indicando que as características da chuva que determinam seu potencial erosivo, principalmente intensidade e quantidade, são muito variáveis. No período em estudo, o máximo valor de erosividade anual, $22.828 \mathrm{MJ} \mathrm{mm} \mathrm{ha}^{-1} \mathrm{~h}^{-1}$ ano $^{-1}$, foi observado em 2002 , e a menor erosividade, $2.239 \mathrm{MJ} \mathrm{mm} \mathrm{ha}^{-1} \mathrm{~h}^{-1}$ ano ${ }^{-1}$, em 1995.

O valor da erosividade média anual das chuvas (fator "R" da USLE) obtido neste trabalho para QuaraíRS (9.292 MJ mm ha ${ }^{-1} \mathrm{~h}^{-1} \mathrm{ano}^{-1}$ ) está dentro da isoerodente estimada por Lago (2000) para a metade sul do Estado do Rio Grande do Sul. Roncato et al. (2004) determinaram para Santa Maria-RS um índice $\mathrm{EI}_{30}$ de $9.026 \mathrm{MJ} \mathrm{mm} \mathrm{ha}^{-1} \mathrm{~h}^{-1} \mathrm{ano}^{-1}$, com base no período de 1996 a 2004, similar ao do presente estudo, embora a precipitação média anual dessa localidade seja maior (ao redor de $1.750 \mathrm{~mm}$ ). Por sua vez, Bertol (1993) determinou para Lages-SC um índice $\mathrm{EI}_{30}$ de $5.694 \mathrm{MJ} \mathrm{mm} \mathrm{ha}^{-1} \mathrm{~h}^{-1}$ ano $^{-1}$, embora a precipitação média anual desta localidade $(1.674 \mathrm{~mm})$ fosse maior que a determinada para Quaraí $(1.359 \mathrm{~mm})$. Já
Morais et al. (1991), estudando as localidades do sudoeste do Mato Grosso, Barranquinho e Flechas, com precipitações de 1.369 e $1.316 \mathrm{~mm}$ respectivamente, similares às do presente trabalho, encontraram valores médios anuais do índice $\mathrm{EI}_{30}$ de 8.493 e 7.830 $\mathrm{MJ} \mathrm{mm} \mathrm{ha}^{-1} \mathrm{~h}^{-1}$ ano $^{-1}$, menores que os obtidos para Quaraí.

O quadro 2 apresenta a precipitação, o índice de erosividade e o coeficiente de chuva Rc médios mensais e anuais. A tendência de distribuição dos valores percentuais mensais da precipitação e do coeficiente de chuva (Figura 1) é similar pelo fato de o coeficiente de chuva considerar a precipitação mensal e a anual. Dos três parâmetros apresentados na figura 1, há relativa melhor distribuição temporal das precipitações, comparada às distribuições da erosividade e do coeficiente de chuva. Assim, observamse valores extremos da precipitação de 4,7 a 11,2 \%, que são maiores no período janeiro-abril (9,7-11,2 \%) e menores em junho-setembro (4,7-6,6\%), enquanto as distribuições da erosividade e do coeficiente de chuva apresentam maior amplitude entre os valores extremos (2,3-14,0 \% e 2,6-14,4\%, respectivamente). Em janeiro-abril observam-se os valores maiores da erosividade $(9,0-14,0 \%)$ e do coeficiente de chuva $(10,8-14,4 \%)$, e os menores, em junho-setembro, com $2,3-5,2 \%$ e $2,6-4,9 \%$ para erosividade e coeficiente de chuva, respectivamente. Os valores começam altos no mês de janeiro $(10,7,12,3$ e $13,0 \%$, para precipitação, erosividade e coeficiente de chuva, respectivamente); logo, atingem um pico no mês de fevereiro, o qual é o maior do ano para precipitação $(11,2 \%)$ e coeficiente de chuva (14,4\%). Continuando no decorrer do ano, os valores vão diminuindo até chegar ao mínimo no mês de agosto $(4,7 \%$ para a precipitação, 2,3\% para o índice $\mathrm{EI}_{30}$ e $2,6 \%$ para o coeficiente de chuva). A partir desse mês, os valores começam a subir e o índice $\mathrm{EI}_{30}$ alcança seu valor máximo (14,0 \%) no mês de dezembro. No período novembro-março a erosividade ultrapassou a precipitação, sugerindo maior potencial erosivo das chuvas nesses meses, o que contrasta com o período abril-outubro, em que a erosividade ficou abaixo da precipitação, com exceção do mês de maio, que teve valores similares de erosividade e precipitação (9,1 e $8,7 \%$, respectivamente). Isso indica o efeito preponderante da intensidade da chuva em caracterizar o seu potencial erosivo (Wischmeier \& Smith, 1958) e quando se deve ter os maiores cuidados na proteção ao solo.

O período de outubro a maio concentrou $85,4 \%$ da erosividade anual (Figura 2), sendo por isso considerado crítico em relação à erosão. Nesse período, práticas de preparo de solo para semeaduras de culturas de verão e de inverno aumentam os riscos de perdas de solo. Assim, o conhecimento da distribuição da erosividade durante o ano contribui para o planejamento adequado das práticas conservacionistas do solo que permitam reduzir os riscos de erosão. 
Quadro 1. Valores mensais, anuais e médios do índice de erosividade $\mathrm{EI}_{30}\left(\mathrm{MJ} \mathrm{mm} \mathrm{ha}^{-1} \mathrm{~h}^{-1} \mathrm{ano}^{-1}\right)$ em QuaraíRS, no período 1966-2003, com as respectivas medidas estatísticas de dispersão

\begin{tabular}{|c|c|c|c|c|c|c|c|c|c|c|c|c|c|}
\hline Ano & Jan & Fev & Mar & Abr & Maio & Jun & Jul & Ago & Set & Out & Nov & Dez & Total \\
\hline 1966 & $1.144,1$ & $1.302,4$ & $1.072,2$ & 833,0 & 231,5 & 440,9 & 493,3 & 20,3 & 495,2 & 319,1 & 593,6 & $2.204,1$ & $9.149,8$ \\
\hline 1967 & 209,0 & 865,0 & 221,0 & 46,3 & 439,8 & 199,4 & 233,1 & 170,4 & 236,6 & 1542,9 & 763,9 & 510,3 & $5.437,7$ \\
\hline 1968 & 78,5 & 402,2 & 928,0 & 61,6 & 153,9 & 142,0 & 155,0 & 54,0 & 605,8 & 441,8 & 639,4 & 424,5 & $4.086,7$ \\
\hline 1969 & 836,4 & 886,9 & 702,3 & 212,6 & $1.625,1$ & 57,1 & 45,6 & 99,3 & 198,7 & 102,5 & 211,9 & 615,8 & $5.594,2$ \\
\hline 1970 & 353,7 & 150,6 & $1.258,4$ & 275,3 & 370,3 & 624,2 & 343,2 & 98,3 & 0,0 & $1.038,5$ & 0,0 & $1.315,8$ & $5.828,3$ \\
\hline 1971 & $1.391,9$ & $1.596,7$ & 0,0 & 10,9 & 746,0 & 210,2 & 163,4 & 202,7 & 125,1 & 21,6 & 232,1 & 919,8 & $5.620,4$ \\
\hline 1972 & 566,8 & $2.742,6$ & 114,4 & 581,1 & 323,6 & 448,2 & $1.416,2$ & 897,6 & 960,4 & 64,4 & 305,5 & 841,7 & $9.262,5$ \\
\hline 1973 & $2.769,2$ & $4.452,3$ & 209,9 & $1.660,3$ & $2.921,7$ & 182,8 & 770,9 & 80,6 & 108,1 & 35,7 & 50,2 & $3.934,4$ & $17.176,1$ \\
\hline 1974 & $2.021,2$ & $1.983,3$ & 0,0 & 281,1 & 51,2 & $1.548,0$ & 286,1 & 211,5 & 482,9 & 560,1 & 879,9 & 949,1 & $9.254,4$ \\
\hline 1975 & $1.144,1$ & $1.302,4$ & $2.005,6$ & 126,9 & $1.534,0$ & 413,8 & 346,9 & 165,9 & 494,9 & 64,6 & 609,2 & 432,8 & $8.641,1$ \\
\hline 1976 & 997,7 & 195,5 & $1.639,0$ & 687,9 & 171,8 & 104,1 & 19,6 & 124,6 & 0,0 & $1.237,6$ & 759,6 & 590,4 & $6.527,8$ \\
\hline 1977 & 487,9 & $3.434,6$ & 207,9 & 553,0 & 111,4 & 0,0 & 844,3 & 78,8 & 727,0 & 701,2 & $2.186,5$ & 547,5 & $9.880,1$ \\
\hline 1978 & 922,0 & 470,7 & 226,6 & 121,5 & 849,1 & 299,0 & 564,4 & 15,9 & 35,8 & 551,7 & $2.193,5$ & 415,4 & $6.665,6$ \\
\hline 1979 & 12,0 & 384,9 & $2.533,5$ & 47,7 & 73,3 & 54,1 & 38,1 & 797,3 & 931,7 & 543,2 & $1.060,5$ & $1.285,0$ & $7.761,3$ \\
\hline 1980 & 619,9 & $1.094,2$ & $1.049,2$ & 742,7 & 304,3 & 62,1 & 0,0 & 194,9 & 8,1 & $1.628,3$ & 344,4 & $1.334,3$ & $7.382,4$ \\
\hline 1981 & $1.133,2$ & $1.446,1$ & 186,1 & 101,6 & $3.509,2$ & 223,0 & 124,7 & 78,0 & 348,1 & 212,0 & 937,1 & 654,0 & $8.953,1$ \\
\hline 1982 & $1.603,6$ & $2.821,0$ & 103,5 & 25,7 & $1.697,8$ & 261,8 & 473,6 & $1.327,7$ & 43,3 & 906,5 & $2.103,6$ & 131,8 & $11.499,9$ \\
\hline 1983 & $1.042,0$ & 268,9 & 168,4 & 139,3 & 793,6 & 634,8 & 233,8 & 168,9 & 257,3 & 339,9 & 280,3 & 43,8 & $4.371,0$ \\
\hline 1984 & $2.172,9$ & $3.270,0$ & $2.864,6$ & 111,7 & 385,0 & 544,5 & 240,3 & 211,3 & $2.004,8$ & $1.747,5$ & $1.534,1$ & 156,9 & $15.243,6$ \\
\hline 1985 & 48,5 & 81,0 & $2.117,9$ & 220,2 & 932,4 & 257,2 & 231,0 & 93,0 & 372,1 & 376,2 & 0,0 & 159,6 & $4.889,1$ \\
\hline 1986 & $1.172,6$ & 951,6 & $4.663,4$ & $1.333,0$ & 281,9 & 164,0 & 0,0 & 262,6 & 372,1 & $1.443,3$ & $2.747,4$ & 487,8 & $13.879,7$ \\
\hline 1987 & $1.728,9$ & 385,2 & $4.877,5$ & 833,3 & 49,8 & 0,0 & 321,3 & 497,7 & $2.172,2$ & 121,8 & 584,5 & 839,2 & $12.411,4$ \\
\hline 1988 & $2.330,6$ & 78,3 & 95,3 & 24,5 & 849,1 & 31,9 & 11,2 & 127,4 & 482,9 & 165,5 & 918,9 & 392,6 & $5.508,1$ \\
\hline 1989 & 254,1 & 0,0 & 560,0 & 557,0 & 42,2 & 0,0 & 94,9 & 184,5 & 54,3 & 333,6 & 332,0 & $1.371,9$ & $3.784,5$ \\
\hline 1990 & $1.449,3$ & $1.930,6$ & $1.317,7$ & $1.860,7$ & 70,3 & 0,0 & 291,5 & 1,9 & 169,1 & 352,8 & $2.671,1$ & $4.498,3$ & $14.613,3$ \\
\hline 1991 & 65,0 & 109,7 & $1.098,5$ & $5.966,7$ & 626,5 & $1.052,9$ & 401,3 & 137,6 & 26,3 & 283,4 & 199,2 & $2.630,0$ & $12.597,1$ \\
\hline 1992 & 195,8 & $3.783,4$ & 868,5 & $2.920,2$ & 813,0 & $1.700,9$ & 402,1 & 36,8 & 433,4 & 153,4 & 119,2 & 880,7 & $12.307,4$ \\
\hline 1993 & $2.507,8$ & 337,1 & 244,6 & 873,2 & $4.366,6$ & 58,4 & 80,7 & 0,0 & 223,0 & $1.045,7$ & $1.791,4$ & 969,5 & $12.498,0$ \\
\hline 1994 & 0,0 & $3.381,9$ & 189,3 & 365,0 & 178,4 & 666,8 & 0,0 & 103,1 & 163,2 & 266,4 & 129,5 & 43,3 & $5.486,9$ \\
\hline 1995 & 166,2 & 63,2 & 684,9 & 201,2 & 11,8 & 62,5 & 477,2 & 0,0 & 192,5 & 226,3 & 137,4 & 16,1 & $2.239,3$ \\
\hline 1996 & $2.627,0$ & 650,3 & 684,4 & $2.714,8$ & 0,0 & 119,1 & 18,6 & 31,0 & 415,1 & 240,4 & 609,2 & 735,2 & $8.845,1$ \\
\hline 1997 & 508,6 & $1.409,9$ & 478,5 & 558,3 & $1.627,3$ & 113,5 & 506,6 & 198,1 & 63,0 & $1.692,4$ & $2.410,8$ & $4.095,8$ & $13.662,8$ \\
\hline 1998 & $6.061,7$ & $1.536,9$ & $2.632,0$ & $1.387,5$ & 66,2 & $1.409,0$ & 259,8 & 29,6 & $1.368,3$ & 106,2 & 480,8 & 496,1 & $15.834,1$ \\
\hline 1999 & 0,0 & $1.797,0$ & 54,9 & 398,4 & 209,6 & 195,5 & 132,3 & 40,8 & 90,6 & 86,0 & 0,0 & 64,0 & $3.069,1$ \\
\hline 2000 & $1.553,9$ & 225,1 & 948,0 & 430,4 & $1.919,4$ & 637,5 & 361,6 & 785,5 & $1.559,2$ & 427,3 & 901,6 & 361,7 & $10.111,2$ \\
\hline 2001 & $1.099,0$ & 430,8 & 362,1 & $3.028,5$ & $2.157,6$ & 91,3 & 128,0 & 211,5 & 482,9 & 560,1 & 879,9 & $1.304,1$ & $10.735,8$ \\
\hline 2002 & $1.144,1$ & $1.302,4$ & $1.072,2$ & 833,0 & 849,1 & 366,7 & 286,1 & 166,0 & $1.260,7$ & 825,0 & $1.959,6$ & $12.762,7$ & $22.827,6$ \\
\hline 2003 & $1.058,3$ & $1.966,5$ & $2.303,7$ & 528,1 & 920,4 & 556,7 & 74,7 & 133,2 & 385,1 & 518,9 & 877,8 & 138,8 & $9.462,2$ \\
\hline Média & $1.144,1$ & $1.302,4$ & $1.072,2$ & 833,0 & 849,1 & 366,7 & 286,1 & 211,5 & 482,9 & 560,1 & 879,9 & $1.304,1$ & $9.292,1$ \\
\hline Máx. & 6061,7 & $4.452,3$ & $4.877,5$ & $5.966,7$ & $4.366,6$ & $1.700,9$ & $1.416,2$ & $1.327,7$ & $2.172,2$ & $1.747,5$ & $2.747,4$ & $12.762,7$ & $22.827,6$ \\
\hline Mín. & 0,0 & 0,0 & 0,0 & 10,9 & 0,0 & 0,0 & 0,0 & 0,0 & 21,6 & 0,0 & 0,0 & 16,1 & $2.239,3$ \\
\hline $\mathrm{DP}$ & $1.141,0$ & 1198,8 & 1194,9 & 1168,1 & 1019,8 & 427,6 & 281,4 & 283,4 & 542,8 & 511,7 & 810,5 & $2.204,5$ & $4.453,0$ \\
\hline $\mathrm{CV}(\%)$ & 99,7 & 92,0 & 111,4 & 140,2 & 120,1 & 116,6 & 98,4 & 134,0 & 112,4 & 91,4 & 92,1 & 169,0 & 47,9 \\
\hline
\end{tabular}

Máx.: valor máximo da série; Mín.: valor mínimo da série; DP: desvio-padrão; CV: coeficiente de variação. 
As análises de correlação de Pearson mostraram alta correlação do índice de erosividade $\mathrm{EI}_{30}$ com a precipitação média mensal $(r=0,92$; significativo a $0,01 \%)$ e com o coeficiente de chuva $(r=0,92$; significativo a 0,01\%) (Quadro 3).
Correlações significativas entre o índice $\mathrm{EI}_{30}$ e o coeficiente de chuva Rc foram observadas também em outras localidades, como os casos de oito regiões do Estado do Paraná (Rufino et al., 1993), Goiânia-GO (Silva et al., 1997), Fortaleza-CE (Silva \& Días, 2003),

Quadro 2. Valores médios mensais e anuais da precipitação pluvial (p), índice de erosividade $\mathrm{EI}_{30}$ e coeficiente de chuva (Rc) de Quaraí-RS, no período 1966-2003

\begin{tabular}{|c|c|c|c|}
\hline Mês & $\mathbf{p}$ & $\mathbf{E I}_{30}$ & Re \\
\hline & $\mathrm{mm}$ & MJ mm ha ${ }^{-1} \mathrm{~h}^{-1} \mathrm{mês}^{-1}$ & $\mathrm{~mm}$ \\
\hline Janeiro & 145,0 & 1144,1 & 15,5 \\
\hline Fevereiro & 152,4 & 1302,4 & 17,1 \\
\hline Março & 132,8 & 1072,2 & 13,0 \\
\hline Abril & 132,2 & 833,0 & 12,9 \\
\hline Maio & 117,8 & 849,1 & 10,2 \\
\hline Junho & 86,3 & 366,7 & 5,5 \\
\hline Julho & 88,7 & 286,1 & 5,8 \\
\hline Agosto & 64,4 & 211,5 & 3,1 \\
\hline Setembro & 89,5 & 482,9 & 5,9 \\
\hline Outubro & 109,4 & 560,1 & 8,8 \\
\hline Novembro & 115,3 & 879,9 & 9,8 \\
\hline Dezembro & 125,5 & 1304,1 & 11,6 \\
\hline Total anual & 1359,4 & 9292,1 & - \\
\hline
\end{tabular}

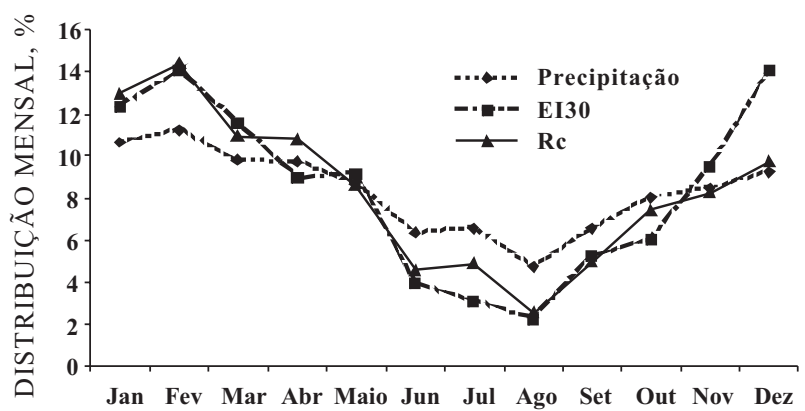

Figura 1. Distribuição percentual mensal da precipitação pluvial, índice $\mathrm{EI}_{30}$ e coeficiente de chuva em Quaraí-RS, no período 1966-2003.

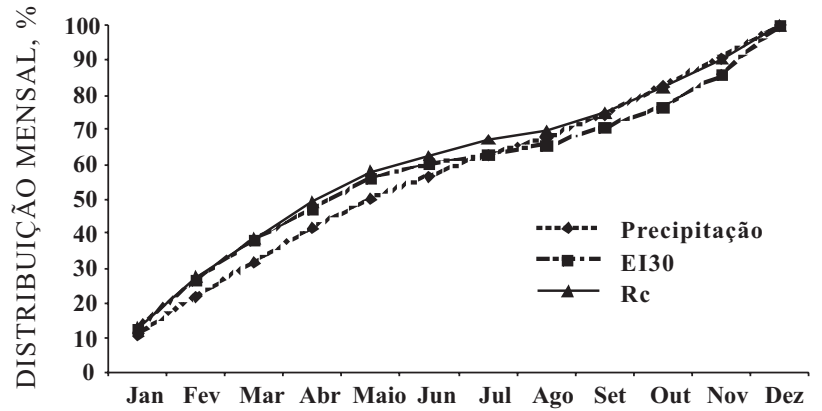

Figura 2. Distribuição percentual acumulada da precipitação pluvial, índice $\mathrm{EI}_{30}$ e coeficiente de chuva em Quaraí-RS, no período 1966-2003.

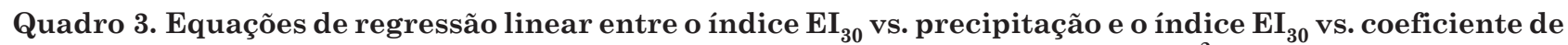
chuva (Rc) para Quaraí, com os respectivos coeficientes de determinação $\left(R^{2}\right)$ e variação $(C V)$

\begin{tabular}{|c|c|c|}
\hline Equação & $\mathbf{R}^{2}$ & CV (\%) \\
\hline $\mathrm{EI}_{30}=-754,37+13,50 \mathrm{p}^{(1)}$ & $0,85^{* * * * *}$ & 20,24 \\
\hline $\mathrm{EI}_{30}=-47,35+82,72 \mathrm{Rc}$ & $0,84^{* * * *}$ & 20,77 \\
\hline
\end{tabular}


Campinas-SP (Lombardi Neto, 1977), sudoeste de Mato Grosso do Sul (Morais et al., 1991), Selvíria-MS (Carvalho et al., 1997) e Piraju-SP (Roque et al., 2001). Correlações não-significativas foram encontradas para a localidade de Campos Novos-SC (Bertol, 1994).

As regressões lineares obtidas foram altamente significativas, sendo as equações $\mathrm{EI}_{30}=-754,37+13,50$ $\mathrm{p} ; \mathrm{R}^{2}=0,85$ (significativo a $0,01 \%$ ), em que $\mathrm{p}=$ precipitação média mensal $(\mathrm{mm})$, e $\mathrm{EI}_{30}=-47,35+$ $82,72 \mathrm{Rc} ; \mathrm{R}^{2}=0,84$ (significativo a $0,01 \%$ ), em que $\mathrm{Rc}=$ coeficiente de chuva $=\mathrm{p}^{2} \mathrm{P}^{-1}$, sendo $\mathrm{p}=$ precipitação média mensal $(\mathrm{mm})$ e $\mathrm{P}=$ precipitação média anual (mm) (Quadro 3). Assim, é possível utilizar as equações para determinar o índice $\mathrm{EI}_{30}$ por meio do uso de dados pluviométricos mensais e anuais. Essa é uma possibilidade de se utilizarem os dados pluviométricos e as expressões ajustadas no quadro 3 para estimar a erosividade das chuvas em locais da mesma região agroclimática, no entorno de Quaraí.

\section{Padrões de chuva}

Aproximadamente metade das chuvas erosivas (51\%) foi classificada dentro do padrão avançado (Quadro 4). O restante das chuvas esteve, quase por partes iguais, classificado no padrão intermediário $(25 \%)$ e no padrão atrasado (24 \%). Em relação ao número total de chuvas anuais, as chuvas erosivas representam $44 \%$, enquanto o volume da precipitação erosiva representa $90 \%$ do volume da precipitação total. Isso quer dizer que $66 \%$ do número de chuvas contribui com apenas $10 \%$ do volume de precipitação. Considerando o volume das chuvas erosivas anuais, a maior proporção correspondeu a chuvas do padrão avançado (57\%), seguido do padrão intermediário $(25 \%)$ e do padrão atrasado (18 \%). Em relação ao padrão hidrológico das chuvas erosivas, $57 \%$ da erosividade correspondeu a chuvas de padrão avançado, $25 \%$ a chuvas de padrão intermediário e $18 \%$ a chuvas de padrão atrasado.

A distribuição das chuvas concentrada no padrão avançado permite esperar menores perdas de solo devido ao fato de que no momento do pico da chuva este estaria menos úmido que no caso dos outros padrões; dessa forma, a desagregação, o selamento e o transporte de solo seriam menores (Mehl et al., 2001). Eltz et al. (2001), trabalhando com simulador de chuva em um Argissolo Vermelho-Amarelo, observaram maior perda de solo em chuvas de padrão atrasado em relação às perdas de solo das chuvas de padrão intermediário e avançado, entre as quais não houve diferenças significativas, o que foi explicado pelas condições de alteração da superfície e pela umidade do solo no decorrer da chuva. No padrão atrasado, quando ocorre o pico de máxima intensidade, o solo está com maior umidade (em relação aos outros padrões), favorecendo a desagregação, o selamento superficial e o transporte de suas partículas, ocorrendo assim maior perda de solo.

\section{Período de retorno}

Os valores de precipitação máxima observados para durações da chuva de 1/6 e 1/3 de hora foram de 40,0 e 50,0 mm, respectivamente, no ano de 1973, ao passo que no ano de 2002 ocorreram as máximas precipitações para durações da chuva de $1 / 2,1,2,4,8,12,24$ e $48 \mathrm{~h}$, alcançando, respectivamente, 63,$5 ; 99,5 ; 151,4$; 216,8; 262,8; 265,5; 266,4; e 287,1 mm (Quadro 5).

Em razão do método empregado para obter os dados de precipitação máxima para as diferentes durações da chuva, os valores aqui apresentados poderiam diferir dos obtidos por Ipagro (1989), a qual considera

Quadro 4. Valores médios anuais de número, volume e erosividade das chuvas erosivas e totais (erosivas e não-erosivas) e distribuição por padrão das chuvas erosivas na localidade de Quaraí, no período 19662003

\begin{tabular}{|c|c|c|c|c|c|c|}
\hline \multirow{2}{*}{ Variável } & \multirow{2}{*}{ Unidade } & \multicolumn{4}{|c|}{ Padrões de chuva erosiva individual } & \multirow{2}{*}{$\begin{array}{c}\text { Total das } \\
\text { chuvas }\end{array}$} \\
\hline & & Avançado & Intermediário & Atrasado & Total & \\
\hline \multirow[t]{3}{*}{ Número } & - & 19,4 & 9,4 & 9,1 & 37,9 & 85,6 \\
\hline & $\%$ das chuvas erosivas & 51,1 & 24,9 & 24,0 & 100,0 & \\
\hline & $\%$ do total das chuvas & 22,7 & 11,0 & 10,6 & 44,3 & 100,0 \\
\hline \multirow[t]{3}{*}{ Volume } & $\mathrm{mm}$ & 698,5 & 302,8 & 228,1 & $1.229,4$ & $1.359,4$ \\
\hline & $\%$ das chuvas erosivas & 56,8 & 24,6 & 18,6 & 100,0 & \\
\hline & $\%$ do total das chuvas & 51,4 & 22,3 & 16,8 & 90,4 & 100,0 \\
\hline \multirow[t]{2}{*}{ Erosividade (Índice EI $\mathrm{EI}_{30}$ ) } & MJ mm ha ${ }^{-1} \mathrm{~h}^{-1}$ ano $^{-1}$ & $5.321,2$ & $2.350,7$ & $1.620,1$ & $9.292,0$ & $9.292,0$ \\
\hline & $\%$ & 57,3 & 25,3 & 17,4 & 100,0 & 100,0 \\
\hline
\end{tabular}


Quadro 5. Precipitação máxima para diferentes durações em Quaraí-RS, no período 1966-2003, com respectivas medidas estatísticas de dispersão

\begin{tabular}{|c|c|c|c|c|c|c|c|c|c|c|}
\hline \multirow{2}{*}{ Ano } & \multicolumn{10}{|c|}{ Duração da chuva (hora) } \\
\hline & $1 / 6$ & $1 / 3$ & $1 / 2$ & 1 & 2 & 4 & 8 & 12 & 24 & 48 \\
\hline 1966 & 20,0 & 26,7 & 30,3 & 41,7 & 42,0 & 42,8 & 43,0 & 44,6 & 58,5 & 91,5 \\
\hline 1967 & 20,0 & 32,0 & 36,0 & 50,0 & 62,2 & 71,2 & 81,9 & 88,6 & 88,6 & 96,4 \\
\hline 1968 & 10,5 & 19,5 & 24,0 & 25,3 & 38,2 & 47,6 & 55,7 & 66,4 & 75,3 & 109,8 \\
\hline 1969 & 17,5 & 22,6 & 25,5 & 31,6 & 45,8 & 62,8 & 77,2 & 97,4 & 127,2 & 127,2 \\
\hline 1970 & 15,0 & 24,0 & 30,0 & 39,0 & 45,4 & 62,0 & 87,6 & 103,9 & 103,9 & 103,9 \\
\hline 1971 & 20,0 & 24,1 & 27,2 & 44,4 & 61,0 & 67,2 & 71,0 & 74,3 & 75,8 & 75,8 \\
\hline 1972 & 20,0 & 40,0 & 56,0 & 71,6 & 79,8 & 93,2 & 113,6 & 145,0 & 165,9 & 165,9 \\
\hline 1973 & 40,0 & 50,0 & 54,7 & 59,1 & 70,4 & 75,2 & 84,0 & 110,0 & 157,1 & 185,1 \\
\hline 1974 & 19,2 & 29,2 & 31,8 & 45,4 & 63,4 & 90,8 & 94,1 & 99,7 & 99,7 & 99,7 \\
\hline 1975 & 20,0 & 29,3 & 32,4 & 37,6 & 51,8 & 57,2 & 64,7 & 71,8 & 72,6 & 72,6 \\
\hline 1976 & 20,0 & 30,0 & 36,7 & 41,0 & 54,2 & 57,6 & 61,3 & 87,4 & 87,4 & 87,4 \\
\hline 1977 & 20,0 & 30,0 & 40,0 & 67,1 & 70,0 & 70,0 & 70,0 & 71,2 & 73,3 & 86,8 \\
\hline 1978 & 14,0 & 20,8 & 27,5 & 31,6 & 45,6 & 64,4 & 86,8 & 97,3 & 165,7 & 176,5 \\
\hline 1979 & 20,0 & 35,0 & 43,4 & 58,5 & 72,2 & 101,6 & 112,8 & 113,3 & 113,3 & 142,3 \\
\hline 1980 & 18,6 & 23,6 & 28,6 & 37,6 & 50,0 & 61,2 & 95,7 & 97,8 & 103,4 & 148,9 \\
\hline 1981 & 17,0 & 25,0 & 34,9 & 45,4 & 72,2 & 106,0 & 149,4 & 151,7 & 185,3 & 186,0 \\
\hline 1982 & 20,6 & 31,3 & 41,6 & 50,0 & 60,0 & 96,8 & 127,9 & 128,4 & 128,4 & 128,4 \\
\hline 1983 & 20,3 & 30,5 & 40,5 & 40,6 & 41,0 & 41,2 & 43,8 & 45,1 & 52,8 & 52,8 \\
\hline 1984 & 20,0 & 30,2 & 37,2 & 51,2 & 67,8 & 97,2 & 100,1 & 106,8 & 107,4 & 122,1 \\
\hline 1985 & 18,1 & 29,7 & 36,0 & 56,0 & 68,0 & 68,0 & 72,7 & 73,9 & 73,9 & 73,9 \\
\hline 1986 & 30,0 & 36,7 & 41,1 & 53,6 & 65,2 & 86,4 & 104,6 & 105,1 & 105,1 & 105,1 \\
\hline 1987 & 27,8 & 32,5 & 36,8 & 56,7 & 63,6 & 98,4 & 124,0 & 144,3 & 121,2 & 186,8 \\
\hline 1988 & 12,6 & 17,7 & 23,9 & 36,7 & 50,8 & 68,4 & 89,5 & 96,0 & 96,2 & 186,2 \\
\hline 1989 & 14,0 & 21,0 & 21,9 & 29,8 & 38,6 & 40,4 & 54,1 & 56,0 & 56,0 & 79,5 \\
\hline 1990 & 20,6 & 29,6 & 36,6 & 61,0 & 90,0 & 130,4 & 178,1 & 227,3 & 227,4 & 227,4 \\
\hline 1991 & 18,7 & 28,9 & 39,2 & 62,5 & 77,8 & 115,2 & 168,8 & 190,8 & 211,3 & 239,5 \\
\hline 1992 & 24,1 & 30,3 & 37,0 & 47,4 & 59,6 & 70,8 & 122,9 & 133,3 & 142,5 & 154,8 \\
\hline 1993 & 17,1 & 28,1 & 34,4 & 55,5 & 84,4 & 103,2 & 189,6 & 191,5 & 191,5 & 220,0 \\
\hline 1994 & 32,0 & 32,7 & 41,2 & 77,4 & 91,8 & 92,0 & 98,1 & 98,1 & 98,1 & 98,1 \\
\hline 1995 & 18,4 & 20,3 & 20,4 & 21,2 & 25,6 & 32,0 & 41,8 & 41,8 & 45,6 & 56,0 \\
\hline 1996 & 15,2 & 23,8 & 35,5 & 51,7 & 54,8 & 80,0 & 86,0 & 97,7 & 133,5 & 152,3 \\
\hline 1997 & 21,0 & 27,3 & 32,2 & 49,7 & 56,2 & 81,2 & 93,0 & 139,8 & 150,0 & 197,9 \\
\hline 1998 & 26,5 & 31,0 & 44,7 & 51,9 & 66,6 & 80,4 & 101,3 & 111,7 & 175,4 & 175,8 \\
\hline 1999 & 20,0 & 30,0 & 32,3 & 38,1 & 40,8 & 42,8 & 57,5 & 59,5 & 60,2 & 136,2 \\
\hline 2000 & 19,5 & 29,5 & 37,6 & 43,0 & 48,6 & 58,0 & 70,3 & 72,2 & 72,2 & 72,2 \\
\hline 2001 & 20,0 & 30,0 & 32,0 & 35,9 & 48,4 & 64,8 & 70,3 & 100,8 & 128,1 & 155,9 \\
\hline 2002 & 33,5 & 48,5 & 63,5 & 99,5 & 151,4 & 216,8 & 262,8 & 265,5 & 266,4 & 287,1 \\
\hline 2003 & 20,0 & 30,0 & 46,9 & 52,5 & 58,6 & 65,6 & 69,2 & 69,7 & 90,7 & 91,4 \\
\hline Média & 20,6 & 29,2 & 36,1 & 48,7 & 61,4 & 77,9 & 96,7 & 107,3 & 118,1 & 135,7 \\
\hline Máx. & 40,0 & 50,0 & 63,5 & 99,5 & 151,4 & 216,8 & 262,8 & 265,5 & 266,4 & 287,1 \\
\hline Mín. & 10,5 & 17,7 & 20,4 & 21,2 & 25,6 & 32,0 & 41,8 & 41,8 & 45,6 & 52,8 \\
\hline DP & 5,8 & 6,7 & 9,1 & 15,0 & 21,2 & 32,3 & 45,0 & 48,8 & 52,1 & 56,1 \\
\hline CV (\%) & 28,1 & 23,1 & 25,3 & 30,8 & 34,5 & 41,4 & 46,6 & 45,5 & 44,2 & 41,3 \\
\hline
\end{tabular}

Máx.: valor máximo da série; Mín.: valor mínimo da série; DP: desvio-padrão; CV: coeficiente de variação. 
a quantidade de chuva entre um período fixo de tempo, ou seja, 24 h, para valores tanto de pluviômetro quanto de pluviógrafo. No presente trabalho, é considerada a precipitação máxima para a duração estabelecida em qualquer período de tempo, ou seja, é considerada a data do início de uma chuva erosiva individual, independentemente de quantos dias possa ter durado.

No quadro 6 são apresentados os valores de intensidade média, desvio-padrão e parâmetro $\alpha$ para diferentes durações da chuva da localidade de Quaraí, calculados mediante o programa Freqrisk (Kite, 1988).

A intensidade da chuva para durações e períodos de retorno utilizados neste trabalho, analisados pela distribuição extrema tipo I (Gumbel, 1958), é apresentada no quadro 7. Um teste de KolmogorovSmirnov realizado mostrou que essa distribuição se ajusta aos dados observados. Os parâmetros das regressões ( $\mathrm{a}$, b e c) entre o log da intensidade e o log da duração da chuva podem ser observados no quadro 8. Obteve-se alta significância estatística (probabilidade menor de 0,01\%) e alto coeficiente de determinação $\left(R^{2}=0,9998\right)$ nas seis regressões dos períodos de retorno considerados. Isso indica que a variação da intensidade como variável da duração é explicada em mais de 99 \% pelo modelo quadrático considerado $\left(\log \mathrm{I}=\mathrm{a}+\mathrm{b}(\log \mathrm{D})+\mathrm{c}(\log \mathrm{D})^{2}\right)$, significando alta confiabilidade nos resultados quando são utilizadas essas equações. Eltz et al. (1992) obtiveram resultados também altamente significativos para a localidade de Santa Maria-RS.

Quadro 6. Valores da intensidade média $(\mu)$, desvio-padrão $(\sigma)$ e parâmetro $\alpha$ para diferentes durações da chuva em Quaraí-RS

\begin{tabular}{crcc}
\hline Duração & $\mu$ & $\sigma$ & $\alpha$ \\
\hline Hora & \multicolumn{1}{c}{$\mathrm{mm} \mathrm{h}^{-1}$} & \\
\cline { 2 - 3 } $1 / 6$ & 20,66 & 10,4355163 & 0,12310 \\
$1 / 3$ & 29,45 & 14,6082169 & 0,08796 \\
$1 / 2$ & 36,20 & 18,1989011 & 0,07061 \\
1 & 48,47 & 25,1634656 & 0,05107 \\
2 & 60,82 & 31,5974683 & 0,04067 \\
4 & 76,52 & 41,3279566 & 0,03109 \\
8 & 93,57 & 52,1152569 & 0,02466 \\
12 & 103,90 & 58,4208867 & 0,02199 \\
24 & 114,50 & 64,9076267 & 0,01980 \\
48 & 132,20 & 74,3437960 & 0,01728 \\
\hline
\end{tabular}

Quadro 7. Intensidade da chuva calculada pelo método da distribuição extrema tipo 1 (Gumbel, 1958), para durações e períodos de retorno selecionados em Quaraí-RS

\begin{tabular}{|c|c|c|c|c|c|c|}
\hline \multirow{2}{*}{ Duração } & \multicolumn{6}{|c|}{ Período de retorno (ano) } \\
\hline & 2 & 5 & 10 & 20 & 50 & 100 \\
\hline \multicolumn{7}{|l|}{ Hora } \\
\hline $1 / 6$ & 113,6 & 168,8 & 205,4 & 240,5 & 285,9 & 320,0 \\
\hline $1 / 3$ & 81,1 & 119,8 & 145,4 & 170,0 & 201,7 & 225,5 \\
\hline $1 / 2$ & 66,4 & 98,5 & 119,8 & 140,2 & 166,6 & 186,3 \\
\hline 1 & 44,3 & 66,5 & 81,2 & 95,3 & 113,6 & 127,2 \\
\hline 2 & 27,8 & 41,7 & 51,0 & 59,8 & 71,3 & 79,9 \\
\hline 4 & 17,4 & 26,6 & 32,6 & 38,4 & 45,9 & 51,5 \\
\hline 8 & 10,6 & 16,4 & 20,2 & 23,8 & 28,6 & 32,1 \\
\hline 12 & 7,9 & 12,2 & 15,0 & 17,7 & 21,3 & 23,9 \\
\hline 24 & 4,3 & 6,7 & 8,3 & 9,8 & 11,8 & 13,2 \\
\hline 48 & 2,5 & 3,9 & 4,8 & 5,6 & 6,8 & 7,6 \\
\hline
\end{tabular}


As curvas que geraram os coeficientes das equações anteriores estão representadas na figura 3. Com o uso dessa figura, é possível estimar diretamente a intensidade, duração e período de retorno da chuva. Considerando duração e período de retorno específico, pode-se determinar a intensidade da chuva para essas condições. De forma similar, partindo de dados de duração e intensidade, chega-se ao período de retorno, e, com os valores de intensidade e período de retorno pode-se encontrar a duração da chuva. Dentro das amplitudes de duração, intensidade e períodos de retorno apresentados no presente estudo, podem ser feitas interpolações. Para extrapolações, a confiabilidade é menor. Em razão de a origem de dados corresponder a uma quantidade de anos limitada (38 anos), os eventos pluviais máximos reais podem ser maiores do que os observados.

Foi ajustada a seguinte equação, que relaciona as características intensidade, duração e período de retorno da chuva:

$$
I=\frac{47,23 T^{0,26}}{(t+0,20)^{0,76}}
$$

em que I é a intensidade máxima da chuva, em $\mathrm{mm} \mathrm{h}^{-1}$; $T$, o período de retorno, em anos; e $t$, o período de duração da chuva, em horas.

Essa equação teve alta significância estatística (probabilidade menor que 0,01\%), alto coeficiente de determinação $\left(\mathrm{R}^{2}=0,9958\right)$ e baixo coeficiente de variação $(\mathrm{CV}=2,30 \%)$. Os valores da intensidade da chuva para durações e períodos de retorno selecionados calculados pela equação 15 são apresentados no quadro 9. Os valores são similares aos obtidos no quadro 7, o qual indicaria que se pode utilizar qualquer uma das equações apresentadas.

As informações que proporcionam a análise de freqüência apresentada no gráfico de intensidadeduração-freqüência (Figura 3) e a equação 15 poderão ser levadas em consideração para dimensionamento

Quadro 8. Parâmetros das regressões (a, b e c) entre log da intensidade da chuva (I), em $\mathrm{mm} \mathrm{h}^{-1}$, e log da duração da chuva (D), em horas, para os períodos de retorno (T) estudados e respectivos coeficientes de determinação $\left(R^{2}\right)$ e de variação $(C V)$ em Quaraí-RS

\begin{tabular}{|c|c|c|c|c|c|}
\hline \multirow{2}{*}{$\mathbf{T}$} & \multicolumn{5}{|c|}{$\log I=a+b(\log D)+c(\log D)^{2}$} \\
\hline & A & $\mathbf{b}$ & c & $\mathbf{R}^{2}$ & $\mathrm{CV}$ \\
\hline Ano & & & & & $\%$ \\
\hline 2 & 1,6395 & $-0,6055$ & $-1,0818$ & $0,9998^{* * * *}$ & 0,5917 \\
\hline 5 & 1,8158 & $-0,5956$ & $-0,0821$ & $0,9998^{* * * *}$ & 0,4947 \\
\hline 10 & 1,9025 & $-0,5921$ & $-0,0821$ & $0,9998^{* * * *}$ & 0,4803 \\
\hline 20 & 1,9719 & $-0,5898$ & $-0,0821$ & $0,9998^{* * * *}$ & 0,4682 \\
\hline 50 & 2,0481 & $-0,5875$ & $-0,0823$ & $0,9998^{* * * *}$ & 0,4601 \\
\hline 100 & 2,0974 & $-0,5863$ & $-0,0823$ & $0,9998^{* * * *}$ & 0,4508 \\
\hline
\end{tabular}

\footnotetext{
${ }_{* * * * *}$ Significativo a $0,01 \%$.
}

Quadro 9. Intensidade da chuva calculada pela equação $I=\frac{47,23 T^{0,26}}{(t+0,20)^{0,76}}$ para durações e períodos de retorno selecionados em Quaraí-RS

\begin{tabular}{|c|c|c|c|c|c|c|}
\hline \multirow{2}{*}{ Duração } & \multicolumn{6}{|c|}{ Período de retorno (ano) } \\
\hline & 2 & 5 & 10 & 20 & 50 & 100 \\
\hline \multicolumn{7}{|l|}{ Hora } \\
\hline $1 / 6$ & 121,1 & 154,2 & 185,2 & 222,5 & 283,4 & 340,4 \\
\hline $1 / 3$ & 91,2 & 116,2 & 139,6 & 167,6 & 213,5 & 256,4 \\
\hline $1 / 2$ & 74,3 & 94,6 & 113,6 & 136,5 & 173,9 & 208,8 \\
\hline 1 & 49,4 & 63,0 & 75,6 & 90,8 & 115,7 & 138,9 \\
\hline 2 & 31,3 & 39,8 & 47,8 & 57,4 & 73,2 & 87,9 \\
\hline 4 & 19,2 & 24,4 & 29,3 & 35,2 & 44,9 & 53,9 \\
\hline 8 & 11,6 & 14,7 & 17,7 & 21,3 & 27,1 & 32,5 \\
\hline 12 & 8,6 & 10,9 & 13,1 & 15,7 & 20,0 & 24,1 \\
\hline 24 & 5,1 & 6,5 & 7,8 & 9,4 & 11,9 & 14,3 \\
\hline 48 & 3,0 & 3,9 & 4,6 & 5,6 & 7,1 & 8,5 \\
\hline
\end{tabular}




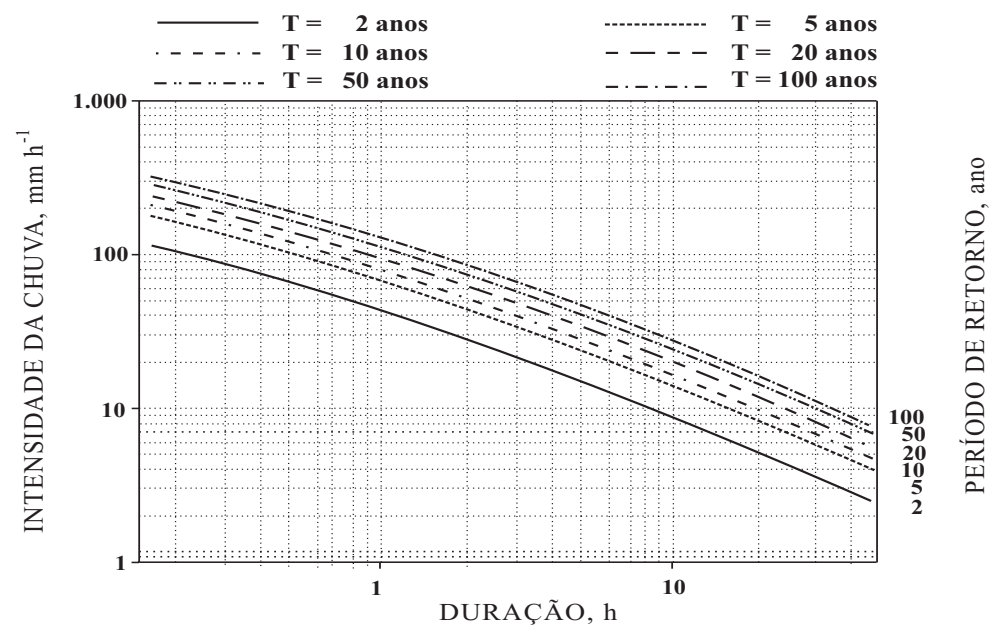

Figura 3. Períodos de retorno esperados (T), em anos, da chuva em Quaraí-RS, como variável da intensidade e duração das chuvas.

de obras de conservação de solo, como canais de escoamento e espaçamento entre terraços, assim como diferentes obras civis. O dimensionamento mais ajustado ou superestimado de uma determinada obra implica, respectivamente, menor ou maior segurança da obra para resistir aos eventos pluviais, sendo as últimas mais onerosas. Assim, um planejamento eficaz deverá levar em consideração esses aspectos.

\section{CONCLUSÕES}

1. $O$ valor do fator $R$ da equação universal de perdas de solo para a localidade de Quaraí é de 9.292 MJ mm $\mathrm{ha}^{-1} \mathrm{~h}^{-1}$ ano $^{-1}$.

2. Obteve-se alta correlação do índice de erosividade $\mathrm{EI}_{30}$ com a precipitação e com o coeficiente de chuva, podendo-se utilizar as equações obtidas para estimar o fator R da USLE.

3. Em Quaraí, RS, o número, o volume das chuvas e a erosividade $\left(\mathrm{EI}_{30}\right)$ corresponderam, em sua maioria, a chuvas classificadas no padrão avançado (51, 57 e $57 \%$ ), seguido do intermediário $(25,25$ e $25 \%$ ) e atrasado (24, 18 e $18 \%)$, respectivamente.

4. Em relação ao total das chuvas estudadas, 44\% do número e $90 \%$ do volume foram erosivas.

5. Os períodos de retorno da chuva em Quaraí podem ser calculados por meio das equações afins, utilizando os valores dos parâmetros encontrados, ou pelo gráfico das curvas de intensidade-duraçãofreqüência.

\section{AGRADECIMENTOS}

À FEPAGRO, pela cessão dos dados, e aos observadores meteorológicos da FEPAGRO, que, no trabalho anônimo, cotidiano, fundamental e imprescindível, realizaram a leitura e anotação das precipitações, possibilitando assim o uso dos dados e a realização deste trabalho.

\section{LITERATURA CITADA}

ALBUQUERQUE, A.W. Determinação da erosividade de Caruaru-PE: 1. Correlação com perdas de solo, 2. Distribuição de probabilidade de ocorrência. Piracicaba, Escola Superior de Agricultura Luiz de Queiroz, 1992. 100p. (Tese de Mestrado)

BEDIENT, P.B. \& HUBER, W.C. Hydrology and food plain analysis. New York, Addison Wesley, 1988. 650p.

BERTOL, I. Avaliação da erosividade da chuva na localidade de Campos Novos (SC) no período de 1981-1990. Pesq. Agropec. Bras., 29:1453-1458, 1994.

BERTOL, I. Índice de erosividade $\left(\mathrm{EI}_{30}\right)$ para Lages $(\mathrm{SC})-1^{\mathrm{a}}$ aproximação. Pesq. Agropec. Bras., 28:515-521, 1993.

CABEDA, M.S.V. Computation of storm EI values. West Lafayette, Purdue University, 1976. 6p. Não Publicado.

CARVAlho, M.P.; CATANEO, A. \& LOMBARDI NETO, F. Parâmetros de erosividade da chuva e da enxurrada correlacionados com as perdas de solo e determinação da erodibilidade de um Podzólico Vermelho-Amarelo de Pindorama. R. Bras. Ci. Solo, 21:279-286, 1997.

CASSOL, E.A.; MARTINS, D.; ELTZ, F.L.F. \& FALLEIRO, R.M. Erosividade das chuvas em Taquari, RS, determinada pelo índice $\mathrm{EI}_{30}$, no período de 1963 a 1999. In: REUNIÃO BRASILEIRA DE MANEJO E CONSERVAÇÃO DO SOLO E DA ÁGUA; MANEJO: INTEGRANDO A CIÊNCIA DO SOLO NA PRODUÇÃO DE ALIMENTOS, 15., Santa Maria, 2004. Resumos expandidos. Santa Maria, Universidade Federal de Santa Maria, 2004b. CDROM 
CASSOL, E.A.; MAZURANA, J.; ELTZ, F.L.F. \& DULLIUS, M.V. Erosividade das chuvas em Porto Alegre, RS, determinada pelo índice $\mathrm{EI}_{30}$, com base no período de 1974 a 2003. In: REUNIÃO SUL BRASILEIRA DE CIÊNCIA DO SOLO, 5., Florianópolis, 2004. Anais. Florianópolis, 2004a. v.1. p.1-4.

DENARDIN, J.E.; FREITAS, P.L.; WÜNSCHE, W.A. \& WENDT, W. Características fundamentais da chuva no Brasil. I. Rio Grande do Sul. Pesq. Agropec. Bras., 15:419-421, 1980.

ELTZ, F.L.F.; MEHL, H.U. \& REICHERT, J.M. Perdas de solo e água em entressulcos em um Argissolo VermelhoAmarelo submetido a quatro padrões de chuva. R. Bras. Ci. Solo, 25:485-493, 2001.

ELTZ, F.L.F.; REICHERT, J.M. \& CASSOL, E.A. Período de retorno de chuvas em Santa Maria, RS. R. Bras. Ci. Solo, 16:265-269, 1992.

FOSTER, G.R.; McCOOL, D.K.; RENARD, K.G. \& MOLDENHAUER, W.C. Conversion of the universal soil loss equation to SI units. J. Soil Water Conserv., 36:355359, 1981.

FOURNIER, F. The effect of climatic factors on soil erosion: Estimates of solids transported in suspension in runoff. [S.L.] Association Hydrologic. Int. Public., 1956. v.38. 6p.

FREITAS, P.L. \& MADEIRA NETO, R.S. Um programa computacional para cálculos dos índices de erosividade das chuvas. In: ENCONTRO NACIONAL DE PESQUISA SOBRE CONSERVAÇÃO DE SOLO, 3., Recife, 1980. Resumos. Recife, SUDENE, 1980.

GUMBEL, E.J. Statistics of extremes. New York, Columbia University Press, 1958. 375p.

HORNER, W.W. \& JENS, S.W. Surface runoff determination from rainfall without using coefficients. Trans.ASAE, 107:1039-1117, 1941.

INSTITUTO DE PESQUISAS AGRONÔMICAS - IPAGRO. Atlas agroclimático do Estado do Rio Grande do Sul. Porto Alegre, Secretaria da Agricultura e Abastecimento, 1989 v.1. $102 \mathrm{p}$.

KITE, G.W. Frequency and risk analysis in hydrology. Littleton, Water Resources Publications, 1988. 257p.

LAGO, J.C. Erosividade das chuvas na metade sul do Rio Grande do Sul. Pelotas, Universidade Federal de Pelotas, 2000. 123p. (Tese de Doutorado)

LOMBARDI NETO, F. Rainfall erosivity - Its distribution and relationship with soil loss at Campinas, Brasil. West Lafayette, Purdue University, 1977. 53p. (Tese de Mestrado)

MEHL, H.U.; ELTZ, F.L.F.; REICHERT, J.M. \& DIDONÈ, I.A. Caracterização de padrões de chuvas ocorrentes em Santa Maria (RS). R. Bras. Ci. Solo, 25:475-483, 2001.

MORAIS, L.F.B.; MUTTI, L.S.M. \& ELTZ, F.L.F. Índices de erosividade correlacionados com perdas de solo no Rio Grande do Sul. R. Bras. Ci. Solo, 12:281-284, 1988a.
MORAIS, L.F.B.; MUTTI, L.S.M. \& ELTZ, F.L.F. Relações entre características físicas da chuva e perdas de solo no Rio Grande do Sul. R. Bras. Ci. Solo, 12:285-288, 1988b.

MORAIS, L.F.B.; SILVA, V.; NASCHENVENG, T.M.C.; HARDOIN, P.C.; ALMEIDA, J.E.L.; WEBER, O.L.S.; BOEL, E. \& DURIGON, E. Índice $\mathrm{EI}_{30}$ e sua relação com o coeficiente de chuva do sudoeste do Mato Grosso. R. Bras. Ci. Solo, 15:339-344, 1991.

MORETI, D.; CARVALHO, M.P.; MANNIGEL, A.R. \& MEDEIROS, L.R. Importantes características de chuva para a conservação do solo e da água no município de São Manuel (SP). R. Bras. Ci. Solo, 27:713-725, 2003.

OLIVEIRA JÚNIOR, R.C. \& MEDINA, B.F. A erosividade das chuvas em Manaus (AM). R. Bras. Ci. Solo, 14:235-239, 1990 .

REBOLLEDO R., H.H. Manual SAS por computadora: Análisis estadístico de datos experimentales. México, Trillas, 2002. 208p.

RONCATO, M.L.; ELTZ, F.L.F.; GRAMINHO, D.H.; STEFANELO, C.; FIGUEIREDO, J.V. \& PEDROSO, R.F. Erosividade mensal das chuvas de Santa Maria de abril 1996 a março de 2004. In: REUNIÃO BRASILEIRA DE MANEJO E CONSERVAÇÃO DO SOLO E DA ÁGUA; MANEJO: INTEGRANDO A CIENNCIA DO SOLO NA PRODUÇÃO DE ALIMENTOS, 15., Santa Maria, 2004. Resumos expandidos. Santa Maria, Universidade Federal de Santa Maria, 2004. CD-ROM

ROQUE, C.G.; CARVALHO, M.P. \& PRADO, R.M. Fator erosividade da chuva de Piraju (SP): Distribuição, probabilidade de ocorrência, período de retorno e correlação com o coeficiente de chuva. R. Bras. Ci. Solo, 25:147-156, 2001.

RUFINO, R.L.; BISCAIA, R.C.M. \& MERTEN, G.H. Determinação do potencial erosivo da chuva do Estado do Paraná através de pluviometria: Terceira aproximação. R. Bras. Ci. Solo, 17:439-444, 1993.

SILVA, J.R.C. \& DIAS, A.S. A erosividade das chuvas em Fortaleza (CE). II - Correlação com o coeficiente de chuva e atualização do fator R no período de 1962 a 2000. R. Bras. Ci. Solo, 27:347-354, 2003.

SILVA, M.L.N.; FREITAS, P.L.; BLANCANEAUX, P. \& CURI, N. Índices de erosividade das chuvas da região de Goiânia, GO. Pesq. Agropec. Bras., 32:515-521, 1997.

WISCHMEIER, W.H. A rainfall erosion index for a universal soil-loss equation. Soil Sci. Soc. Am. Proc., 23:246-249, 1959 .

WISCHMEIER, W.H. \& SMITH, D.D. Predicting rainfall erosion losses: A guide to conservation planning. Washington, USDA-Agricultural Research, 1978. 58p. (Agricultural Handbook, 537)

WISCHMEIER, W.H. \& SMITH, D.D. Rainfall energy and its relationship to soil loss. Trans. Am. Geophys. Union, 39:285-291, 1958. 